\title{
The role of sensors and controls in transforming the energy landscape
}

\section{Aileen Richardson, Dale Keairns, Briggs White}

Aileen Richardson, Dale Keairns, Briggs M. White, "The role of sensors and controls in transforming the energy landscape," Proc. SPIE 10639, Micro- and Nanotechnology Sensors, Systems, and Applications X, 106390Y (8 May 2018); doi: 10.1117/12.2303722

SPIE. Event: SPIE Defense + Security, 2018, Orlando, FL, United States 


\title{
The Role of Sensors and Controls in Transforming the Energy Landscape
}

\author{
Aileen Richardson ${ }^{1}$, Dale Keairns ${ }^{1}$, Briggs M. White ${ }^{2}$ \\ ${ }^{2}$ Crosscutting Research Program, National Energy Technology Laboratory, U.S. Department of \\ Energy, 626 Cochrans Mill Rd., Pittsburgh, PA 15236 \\ ${ }^{1}$ Deloitte Consulting LLP, 30 Rockefeller Plaza, New York, NY 10112
}

The U.S. Department of Energy funds a large portfolio of fossil energy R\&D projects aimed at transformational improvements in the cost and environmental performance of coal-based power generation while maintaining high reliability standards. The National Energy Technology Laboratory (NETL) manages DOE's Crosscutting Research Program, which leverages on-going trends in disruptive technology to achieve breakthroughs in sensors and controls. Examples include: advanced manufacturing of embedded sensors with energy harvesting capability; wireless signal transmission and blockchain infrastructure; and the application of data analytics and machine learning to processing distributed sensor signals to create actionable control interfaces. The fossil energy application space requires the development of sensors capable of monitoring key operational parameters (temperature, pressure, and gas compositions) while operating in harsh environments; analytical sensors capable of on-line, real-time evaluation and measurement to support condition-based monitoring. Controls development centers around self-organizing information networks, algorithms for component lifetime assessment and plant-level economics, and distributed intelligence for process control and decision making. All of this must be accomplished while hardening fossil energy assets.

An overview of DOE's Fossil Energy R\&D Program with an emphasis on Sensors and Controls will be presented including discussion of technologies and applications being pursued and their status.

Keywords: Fossil Energy, Power Generation, Harsh Environments, Sensors, Controls, Blockchain, Reliability

\section{INTRODUCTION}

Coal-fired power plants are under growing pressure to operate with higher efficiency, cleaner emissions, and enable efficient and reliable applications with intermittent renewable energy sources. Advanced sensor hardware and control software are becoming increasingly available and providing a reliable means of meeting these demands ${ }^{1}$. Sensors placed throughout the plant, paired with real-time analytics and advanced algorithms help to optimize plant operations and control responses. While there are limitations to the current sensor technology, in particular for combustion processes, research and development is being carried out for advanced sensor and control concepts to enable coal-fired power plants to work in tandem with the changing energy landscape.

\section{THE CHANGING ENERGY LANDSCAPE}

The U.S. energy landscape was built around the dominance of coal. For over 50 years, more than $50 \%$ of the U.S energy was generated by coal ${ }^{2}$. These large facilities produced mass quantities of electricity that fed into a central distribution system that would power the nation, as the large coal facilities were designed to operate non-stop, providing a continuous supply of energy. Since 2005 , there has been shifts in the energy landscape. The fluctuating price of gas, paired with new found natural gas reserves compete with coal to provide competitive energy generation. Furthermore, a civic push for cleaner energy has further strained not only the demand for coal supplied energy, but also strained coal plant ability to remain economical. Energy transition has taken hold of public sentiment and scientific research, and is driving electric utilities to add a new element to their mandate, sustainability. As renewable energy sources have become increasingly available, the role of coal plants will change resulting in an integrated system that responds to periods when renewables cannot meet demand. This evolving transition toward a distributed energy resource (DER) system utilizes a greater mixture of energy resources, and draws upon more local supplies than the previous centralized system. This change is influenced by several factors including technological advances, and changes in environmental regulations.

Micro- and Nanotechnology Sensors, Systems, and Applications X, edited by Thomas George,

Achyut K. Dutta, M. Saif Islam, Proc. of SPIE Vol. 10639, 106390Y · @ 2018 SPIE

CCC code: $0277-786 X / 18 / \$ 18 \cdot$ doi: $10.1117 / 12.2303722$ 
The growing social responsibility to create and use clean energy resources is driving change that directly influences the energy landscape. Automakers are developing electric, low-fuel, and autonomous vehicles; corporations are constructing energy efficient and net-zero energy buildings; and, residential homes are choosing to switch to mixed energy resources to power their utilities. These changes are yielding higher energy efficiencies, but causing energy demand to remain stagnate, despite the growing economy. Furthermore, industry is also using advanced manufacturing techniques and technological innovation to develop products more efficiently and effectively, further reducing their energy footprint. While efficiency concerns are growing on the consumer side of energy, it is forcing producers to also evaluate energy production. The next-generation of analytics and computing are allowing for an integrated industrial energy infrastructure, that aims to integrate and optimize systems and controls to create a modern, and efficient energy ecosystem. In 2015, U.S. electric utilities spent over $\$ 100$ billion in capital expenditures to maintain and upgrade the grid $^{3}$. While this investment is significant, and represents the priority that energy producers are putting on maintaining the grid, tighter emission regulations, greater reliability expectations, and the aging transmission and distribution system will need more than just maintenance, but rather requires extensive upgrades and replacements ${ }^{4}$. The Internet of Things (IoT) provides practical applications that can help move electric companies forward in conjunction with this changing landscape. IoT helps to integrate sensing, communications, and analytical capabilities which can help the electric system in three critical phases: 1) gather data from sensors; 2) synthesize data to actively manage assets and resources; and 3) optimize decision processes throughout the plant from the gathered, synthesized data. Other technological advances, such as blockchain are also helping to revolutionize the energy landscape. The Energy Web Foundation (EWF) expects that blockchain technology can streamline and enhance certificates of origin markets, to become more secure, robust, lower cost, and integrated, to enable an increase in worldwide participation of renewable generators 5 .

As the electric grid becomes more and more connected there is a growing concern for keeping the U.S. energy infrastructure secure. The current administration has placed a significant priority on cybersecurity. The U.S. Senate's Energy and Natural Resources Committee warns that cybersecurity threats could cause potentially "economically devastating blackouts 6 ". Energy Secretary Rick Perry has warned the government that the DOE and the federal government does not have adequate strategies in place to address the thousands of potential cyber-attacks that the U.S. faces daily. In March 2018, the U.S announced that Russian hackers had targeted the energy infrastructure, specifically, a nuclear power plant in Kansas. This attack targeted both the informational technology as well as operational technology that could affect the plant's operations and distribution. As Secretary Perry stated, the U.S. does not have a strategic cybersecurity policy in place to predict and prevent these attacks that are a growing international concern. Furthermore, as energy technology utilizes and embraces for technological changes, integrating systems online through the IoT, it is especially important to simultaneously develop a strong cybersecurity strategy and protocol to protect the U.S. energy infrastructure. The need to develop sound policy is imperative to providing a reliable and secure energy resource in conjunction with the changing energy landscape.

\section{THE CHANGING ENERGY LANDSCAPE: COAL PERSPECTIVE}

While energy producers are preparing for a more efficient energy landscape, the coal generating fleet has particularly been hit by the changes to the energy ecosystem. For decades power generated from coal accounted for more than half of the total share of generation in the United States, and overall energy demand during those years had steadily increased ${ }^{7}$. However, since 2008 the total electric generation in the U.S. has been stagnate, and coal's share of the total generation has sharply declined, from accounting for $50 \%$ in 2005 to $30 \%$ by $2016^{8}$. Since 2010 , more than 420 coal units have shuttered their operations, with a combined capacity of more than 60 gigawatts (GW). To combat the loss, the electric industry has added a mixture of natural gas, renewables, and nuclear power to supplement the aging, and retiring coal infrastructure.

This change in the energy landscape, is causing a shift toward a distributed energy resource system. Consumers are becoming more cognizant of the energy they consume and the externalities associated with that consumption. The push to using more renewable, and especially local resources is changing the energy ecosystem, causing challenges 
for power generators and utilities that are grouped into four major concerns. First, the need to improve the operating efficiencies within the installed fleet by bringing them up to industry standards. Second, the need to reduce the time spent in unplanned outages and improve plant reliability to ensure the ability to remain cost competitive. Third, the pressure to find a way to meet regulatory environmental policies. And lastly, the need to develop a plan to increase renewables and have more flexible operations overtime while remaining profitable ${ }^{9}$. Over the past decade, plants unable to meet these challenges have been forced to retire due to several technological, market and non-market conditions.

The existing fleet is aging and facing increasing challenges to remain cost competitive when compared to other energy resources. Not only does the age of the existing fleet impact the generating efficiency, but it is becoming more expensive to operate, and in many cases, lacks environmental controls necessary to meet governmental regulations. More than $85 \%$ of the U.S coal-fired generating units were built between 1950 and 1990 . The average age of a coal fired unit is 39 years; whereas the average age the overall generating fleet is ten years younger in the U.S. ${ }^{10}$ In general, the older plants are more susceptible to rising operations and maintenance costs and face rising competition from modern technologies. As plants operate under flexible operations to allow for more renewables to access the grid, maintenance costs increase as the plants are unable to operate efficiently during cyclic load following. It is estimated that if a plant undergoes 1 to 12 cold starts per year, there is an additional \$490/MW cost in maintenance ${ }^{11}$, as the cycling under extreme conditions causes increase damage to plant equipment and decreases the life expectancy of the plant.

Plants that are unable to cover the operating costs of the facilities through sales, payments and services are often forced to retire. Despite the increasing number of retiring plants, and challenges that the existing fleet is facing, coal is expected to remain a dominant resource in the U.S energy landscape. The existing fleet is now challenged with being prepared to initiate digitization and optimization strategies to improve operating efficiencies and plant flexibility. In addition to technological advances to improve efficiencies, it is also necessary to pursue advanced materials that can withstand extreme operating conditions. These advances aid in mitigating the increased number of cold starts that a plant is expected to endure in the future. Creating materials that can endure this environment requires advanced data analytics, materials science, and manufacturing techniques.

Coal plants play a vital role in the U.S. economy and their ability to adapt to the changing energy ecosystem is important for several reasons. Coal has a close relationship to manufacturing, as advanced manufacturing techniques can help improve overall efficiencies of the plant. They can help revitalize the manufacturing industry in the U.S. Using coal as a base energy resource can also increase the U.S.' global competitiveness as it provides a low-cost, consistent form of energy that can propel industry. Coal is also an important resource in maintaining the U.S.' energy dominance and dependence. Recently the U.S. has become a net exporter of energy, in large part due to increased natural gas production, but without coal reserves and production, the U.S. would be more reliant on other countries to meet its energy demands. Lastly, coal plants impact the U.S. economic growth in a number of ways, not only do coal power plants support an entire industry, but all industries are dependent upon a secure and reliable source of energy to provide the means of product production. Therefore, economists have concluded that energy is necessary for economic growth, consequently coal power plants ability to produce and generate a reliable source of energy to promote economic growth ${ }^{12}$.

In addition to creating flexible materials that can withstand the changing energy landscape, there is also a need to enhance plant's infrastructure resiliency. In 2017, Hurricanes Harvey, Maria and Irma are expected to have caused over $\$ 250$ billion in economic damages throughout the region, in part due to weak energy infrastructure. While power was restored quickly to most residents, the effects of the hurricanes highlighted the need for resilient energy infrastructure. The goal of updating the infrastructure must be done in conjunction with enhancing digitization and optimization strategies of the plant.

NETL's Crosscutting Research Program has identified three opportunities that coal power plants need to address and focus on to align with the government's energy future vision. These opportunities have been grouped into the 
following three categories: 1) embrace the digital transformation; 2) utilize advanced Industry 4.0 principles; and 3) advanced manufacturing.

\section{Embracing the Digital Transformation}

Industry estimates that over the next decade there will be over one trillion dollars of value added to the digital transformation of electricity. This process will include updating software, performing advanced data analytics, and implementing advanced hardware processes and controls throughout the plant ${ }^{13}$. In addition, the EEI Finance Department predicts that U.S. electric companies will spend more than $\$ 100$ billion on capital expenditures to maintain and upgrade the current grid infrastructure. This upgrade will include technological innovations including blockchain technologies, high-performance computing, machine learning algorithms, the Internet of Things, and advanced manufacturing techniques. As power plants become more digitized, there is an increase focus on cybersecurity and the effects of bringing a power plant online, causing increased federal regulations and guidelines to ensure energy efficiency and reliability. Despite this growing threat, utilities will continue to add thousands of smart devices to their operations as they are essential components to increasing plant efficiency and operations; this accentuates the need for flexibility of utilities, researchers, and government as they navigate the digital complexity of power systems.

One of the driving factors in embracing the digital transformation is using technological disruptors and innovative processes to push technology to the next-generation capacity. For example, blockchain technology is being used to improve utility billing processes, and to promote transactive energy, or engaging in two-way price negotiation based on real-time combinations of user preferences and grid needs. Powerplants have relatively high fixed costs that go toward grid upkeep, and power delivery that are owned and operated by the utility companies; therefore, renewable energy sources, as of yet, are not contributing funds toward their maintenance. The stagnate electricity growth is putting increase pressure on utilities to cover fixed costs. By using blockchain technology to set rates and disrupt the billing cycle, utilities hope to offset some of the challenges they face. This technology is highly dependent upon other technological advances including high-performance computing, and machine learning algorithms that are able to process and synthesize large quantities of data throughout the plant. Data collected at the plant is vital in enhancing technologies that are capable of furthering plant reliability and improving efficiency of key plant components that can lead to transformational savings, such as reducing fuel expenses. Additional benefits include reducing emissions and predicting required maintenance, therefore decreasing unplanned outages. Highperformance computing enables large-scale modeling of fully integrated systems that can be used to develop and test materials for use in extreme environments for power generation and the conversion, use, storage, and transmission of energy ${ }^{14}$. Lastly, the Internet of Things (IoT) is easily coupled with big data analytics to provide accurate performance metrics, tools to manage emissions, and decision support services across the generating fleet. IoT provides a suite of technologies that allows for instant data analysis and smart action. In particular, IoT improves reliability of operations by minimizing risks and disruptions; optimizes operations by allowing for an optimized supply chain; and, creates new value by enhancing revue streams. IoT applications offer a range of possibilities for electric utilities, including data gathering, synthesis, and optimization. Advances in computing, databases, and analytical tools allow for the rapid application of predictive and prescriptive analytics to large volumes of supervisory control and data acquisition (SCADA), and advanced metering infrastructure (AMI) ${ }^{15}$. The ability to efficiently process this data with IoT applications is increasingly important as the modern grid evolves from a oneway, central system, to a platform that not only detects, but also accepts and controls decentralized consumption and production of energy in an intelligent grid system. This system is heavily reliant on sensors and controls that can enable the flexibility and agility the existing fleet needs to remain competitive and efficient. 


\section{Utilizing Advanced Industry 4.0 Principles}

Industry 4.0 integrates advanced production and operation techniques with smart digital technologies, enabling an interconnected network that will allow for greater knowledge sharing, as well as improve operational efficiencies. It represents the movement to integrated, advanced production and operation techniques with smart, digital technologies to create an interconnected network that will allow for faster data sharing and analysis. The result of Industry 4.0 yields a decentralized decision process that allows for real-time data and analysis to drive decision making, moving away from traditional linear data sharing. A process known as the physical-to-digital-to-physical (PDP) loop, which allows for the interconnectedness between physical and digital technologies ${ }^{16}$. An integrated system would reduce operational costs, increase efficiency, allow for a continuous rise in technological innovation, improve product agility, and increase plant agility. While Industry 4.0 is most associated with manufacturing, smart technologies can transform how parts and products are designed, made, used and maintained, and it's PDP loop amplifies the data collected throughout power plants, enabling a continuous and cyclical flow of information between physical and digital worlds ${ }^{17}$. Processing mass quantities of data and using, processing, and sharing it simultaneously is next-generation technology, that sensors and controls can help enable.

A combination of next-generation analytics and computing allows for greater efficiencies across a broad spectrum of energy applications, including process systems, an automated workforce, and advanced manufacturing. The existing fleet needs to leverage the unique capabilities of innovation and research in the field of analytics and computing to bring about transformational changes in the energy landscape to remain competitive and effective. Industry 4.0 principles help to drive to a smarter electrical grid. Using these technological advances can help to predict, manage, and control an increasingly decentralized and complex network.

Not only are these technological changes important in adapting to the changing technological landscape and allowing for greater plant resiliency and reliability, but these changes are also fundamental in allowing the existing fleet to meet and rise above the changes in environmental regulations.

\section{Advanced Manufacturing}

Advanced manufacturing is a significant technological innovation that helps to eliminate performance trade-offs in two fundamental pathways: 1) reducing the capital required to achieve economies of scale; and 2) increases flexibility and reduces the capital to achieve scope ${ }^{18}$. In addition, advanced manufacturing allows for unique opportunities such as: increase scalability, greater control and visibility, and enhanced customization capabilities. These assets are particularly important for fossil fuel energy technologies that need to be produced cost-efficiently, and with unique specifications to endure the extreme operating environments exuded at a power plant. In particular, 3D printing has allowed for rapid prototyping of next-generation technologies that are essential in creating robust, efficient technologies at the plant. One's ability to customize the manufacturing of these unique technologies across the different existing infrastructure allows for quicker introduction of technologies that are improving plant performance and reliability.

U.S. DOE national laboratories are leveraging additive manufacturing techniques in conjunction with high performance computing to build out capabilities that support the advancement of fossil fuel energy. State of the art computational modeling tools are being used to create and apply advanced materials to promote next-generation technologies that support plant integration that improves plant efficiency and allows for large-scale integration with renewable energy sources. Advanced manufacturing revamps the nature of supply chains, creating digital supply chains capable of designing, and creating products anywhere. Lawrence Livermore National Laboratory is leading a consortium to additively manufacture metals that use advanced sensors that operate in build-chamber environments and can be used to feedback to the processes. The strategy uses Stanford University's Institute for Computational and Mathematical Engineering (ICME) to shift the emphasis away from expensive manufacturing processes to modeling and simulation of material characterization.

In many ways, advanced manufacturing is the tool that is driving fossil fuel power plant's ability to embrace other digitization and Industry 4.0 principles, as it enables the production of technologies that allow for the plant to become a more integrated, online system. Flexible innovation practices are pivotal to additive manufacturing and is 
crucial in supporting the pathway that leads to Industry 4.0 principles including product lifecycle management, and resource planning. Furthermore, there is a need for advanced manufacturing to work in tandem with IT cycles to work toward joint innovative practices in order to avoid a technological debt that is focused solely on IT cycles without integrating with advanced manufacturing processes ${ }^{19}$.

\section{THE ROLE OF SENSORS AND CONTROLS IN THE FUTURE OF ENERGY GENERATION}

While this paper thus far has discussed some of the megatrends that are changing the U.S. energy outlook, this section will describe technologies that are at the forefront of enabling these technologies and bring next-generation levels of efficiency and reliability to the existing fleet. Sensors and controls play a pivotal role in the future of energy generation in the U.S. These small, cost-effective devices are being developed to monitor plant operations and components under extreme environments. NETL's Crosscutting Research Program supports a Sensors and Controls program that is dedicated to advancing the development and application of cost-effective sensors and controls $^{\mathrm{a}}$

\section{Exhibit 1: Fossil Energy Domain}

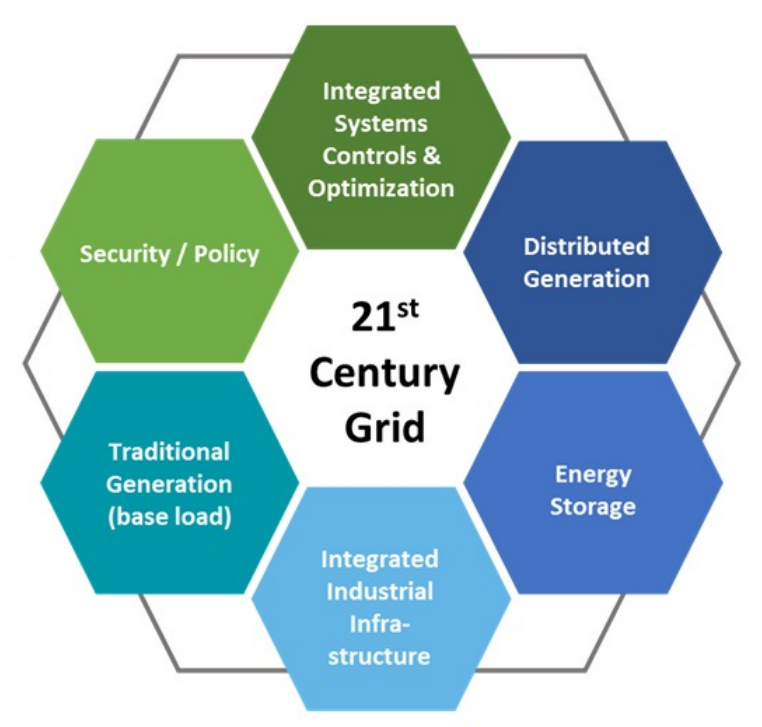

Sensors and controls provide opportunities to advance the future of energy generation. DOE research at NETL is focused on providing technologies that enhance plant performance through embedded, smart sensors, and the use of additive manufacturing to produce and manufacture the technologies. However, sensors and controls also have wider energy generation application and can also impact transmission and distribution, delivery, storage, and the integration of the entire bulk power system. This paper discusses the four main areas for sensors and control research: 1) Coal-Fired Plant Sensor and Control Systems; 2) Reliable Integration of the Power System; 3) Advanced Manufacturing Techniques; and 4) Cybersecurity.

\footnotetext{
${ }^{\text {a }}$ A full portfolio of current Sensors and Controls projects can be found here: https://www.netl.doe.gov/research/coal/crosscutting/project-information\#sac
} 


\section{Coal-Fired Plant Sensor and Control Systems}

Next-generation sensor control systems can be placed throughout a power plant to monitor key parameters such as temperature, pressure, fluid composition, and the state of materials (for example, corrosion, stress). These systems can provide real-time measurement of critical plant properties such as temperature, gas composition, and pressure. This data is then transmitted either wirelessly or through various channels such as acoustic waves, or fiber optics to a control network that processes and reports the data. The data collected from the sensors can be processed to maximize plant efficiency, improve plant maintenance, and optimize asset utilization through lifecycle analysis. Furthermore, with advanced sensor and control systems and algorithms, condition-based monitoring capabilities are improved, allowing for better predictive maintenance of plant operations, and increased knowledge of materials lifecycle. This further enhances a plant's efficiency and reliability.

Currently, NETL is sponsoring the prototype of a Dry Low-NOx (DLN) fuel injector, designed by the University of Texas at El Paso. This work enables sensing capabilities at elevated temperatures, using electron beam melting (EBM) additive manufacturing processes. This project is expected to propel the design and fabrication of EBM advanced manufacturing techniques, and enable the development of novel sensors capable of withstanding extreme operating conditions. This will process drastically cut the time needed to fabricate and embed sensors in fuel injectors, and increase control processes of gas turbine combustors.

A seamless network of integrated sensors and controls embodies the principles of an integrated network that the IoT promotes, having full access to data to ensure greater knowledge and allow greater efficiencies and reliability. There is a growing interest in developing new sensors and controls for the fossil fuel sector that is partly a consequence of rapid advances in a number of technologies which have outpaced their adoption as commercial devices, despite the increasing need to optimize coal plants. This research is valuable to increasing the efficiency and reliability of the existing fleet for the design of next-generation systems. The DOE has estimated that the yearly savings provided by a smart control system would amount to $\$ 360$ million, and $14 \mathrm{MtCO}_{2}$ if applied to the country's entire coal fleet ${ }^{20}$. This savings, paired with reducing emissions is extremely important to combatting the challenges that the existing fleet is facing as described in the sections above.

\section{Reliable Systems Integration}

The ability to accurately model the integrated power system is important given the highly complex and interconnected nature of the power grid. Systems modeling is critical for power grid operations and planning for both normal operations and disturbances to ensure reliable operation of the bulk power system (BPS) ${ }^{21}$. Sensors enable technologies that help achieve this goal through various integrated systems. In addition, an integrated system of process controls can help a plant prepare for and be able to operate flexibly to enable load-following cycles as more renewable sources become available on the grid.

Sensors and controls provide key technologies that enable coal-fired power plants to operate more efficiently and also utilize the technological changes that are shaping the current energy ecosystem. Sensors and controls embody and enable Industry 4.0 PDP loop by providing continuous processing of data. Sensors and controls also help digitize and optimize plant performance and do so while furthering advanced manufacturing techniques that not only help create robust, low-cost sensors, but also spur and innovate techniques that can be used beyond sensors and controls as well. While sensors and controls provide immense data and knowledge and are some of the backbone technologies that is propelling both existing and future generation coal plants forward to meet the challenges of today's energy landscape, there are still some gaps and limitations that provide opportunities for future researchers. 


\section{Cybersecurity}

Cybersecurity also plays an important role in the development of successful sensors and controls. As technology is capable of bringing more and more pieces of the power plant online, it is important to develop sensors and controls that maintain and upgrade the security of the plant in order for the infrastructure to continue to provide secure and reliable source of energy. The shift toward a smart grid will add thousands of smart devices to power plant operations that will need to prepare for enhancing cybersecurity capabilities of both IT and OT systems. Not only will devices be added to increase the plant's ability to operate online, but changing cyber technology including blockchain can be used to further change the energy landscape and utility sector.

The Georgia Tech Research Corporation is partnered with NETL to implement software development that can enact real-time cyber physical systems that simulate process dynamics on the order of five milliseconds or smaller. This important milestone would enable dynamic operability and full-response capabilities of dynamic systems. The federal government supports initiatives that are focused on accelerating research, development, and demonstration of integrating advanced manufacturing in secure and trusted cyber physical systems.

\section{Advanced Manufacturing}

NETL's Sensors and Controls program works toward developing a wide range of sensors and controls to enhance plant performance and resiliency. Using advanced manufacturing techniques, the program can develop low-cost, replicable, and robust sensors that can be placed in key plant components such as boilers and turbines. The controls development centers around artificial and distributed intelligence for process control and decision-making in networks. Improved process control allows for more efficient operation during transient conditions providing more stable operation with tighter environmental control. Modeling and simulation allows for optimization of design, experiments, and data mining, and uncertainty quantification that can greatly improve advanced manufacturing capabilities.

Promising technologies being developed at NETL include using additive topology manufacturing techniques to embed a suite of sensors into the gas turbine airfoil within the power plant. This sensor is capable of providing realtime diagnostics that help to improve turbine reliability and increase fossil fuel utilization. Additionally, smart manufacturing techniques such as 3D printing fabrication and characterization is being tested by the University of Texas at El Paso to develop smart, embedded sensors for a variety of applications that can improve power plant efficiency and resiliency ${ }^{22}$. These embedded sensors, using advanced manufacturing techniques greatly reduce cost, time, and wasted resources.

\section{CONCLUSION}

Electrical utilities are reigning players in a century-old industry that has consistently dealt with disruption driven by new technologies, regulations, and market size. Utilities have consistently adapted and embraced new technologies to improve efficiency and reliability and have been able to grow and expand with the changing economic landscape. The current energy revolution is no exception. National laboratories, such as NETL, and private industry are working together and with academic research institutes to propel utilities to next-level efficiencies and plant operation. Effectively utilizing technological advances such as advanced manufacturing, Industry 4.0 principles, and digitization and optimization strategies, coal-based plants will continue to adapt to the changing energy landscape. Sensors and control technologies are at the forefront of this technological revolution, enabling reliable systems integration, furthering cybersecurity processes, and enhancing plant operations. Not only will sensors and controls continue to play a pivotal role in optimizing plant operations, but will also lead the technological advancement of coal-fired power generation, and allow for the seamless integration of renewables and DERs to the grid system, paving the way for the modern energy ecosystem. 


\section{REFERENCES}

[1] Budman, M., Khan, A., and Cotteleer, M., “Forces of change: Industry 4.0," Deloitte Insights, 1-20, (2017).

[2] "Coal-Fired Electricity Generation in the United States and Future Outlook," MJB\&A Issue Brief, 1-14 (2017).

[3] "Distributed Energy Resources: Connection Modeling and Reliability Considerations," North American Electric Reliability

Corporation, Distributed Resources Task Force Report, (2017).

[4] “DOE Laboratories Sign Memorandum of Understanding for Innovative Coal Research," March 6, 2018.

[5] EEI Finance Department, Company Reports, S\&P Global Market Intelligence, (August 2016).

[6] "Future of Energy: Digital for Coal-Fired Plants," GE Power Digital Solutions, (2017).

[7] Grant, C., McCue, J., and Young, R. "The Power is On: How loT Technology is Driving Energy Innovation," Deloitte Center for Energy Solutions, Deloitte University Press, 1-24, (2016).

[8] Grol, E., Tarka, T., Myles, P., Bartone, L, Simpson, J., and Rossi, G. "Impact of Load Following on the Economics of Existing Coal-Fired Power Plant Operations," DOE/NETL - 2015/1718, (2015).

[9] Hiskey, T., "Preparing for Manufacturing's Future with Industry 4.0", Industry Week, http://www.industryweek.com/print/259440 accessed March 20, 2018.

[10] "Investigation of Smart Parts with Embedded Sensors for Energy System Applications," National Energy Technology Laboratory, Project Description, https://www.netl.doe.gov/research/coal/crosscutting/project-information/proj?k=FE0012321, accessed March 20, 2018.

[11] Lockwood, T., "Advanced sensor and smart controls for coal-fired power plant," IEA Clean Coal Center, No. 21, (2015). [12] Louis, M., Seymore, T., and Joyce, J. "3D Opportunity in the Department of Defense: Additive Manufacturing Fires Up," Deloitte University Press, (2014).

[13] Miller, D. and Henly, C. "Blockchain is Reimagining the Rules of the Game in the Energy Sector," Rocky Mountain Institute, (2017), https://www.rmi.org/news/blockchain-reimagining-rules-game-energy-sector/, accessed March 20, 2018.

$[14]^{\text {a }}$ Starks, T., "U.S. says Russian hackers targeted American energy grid," Politico, (2018),

https://www.politico.com/story/2018/03/15/dhs-fbi-russia-hackers-targeted-energy-grid-813745, accessed March 20, 2018.

[15] Stern, D., "The Role of Energy in Economic Growth," Crawford School of Climate Economics and Policy, Paper No 3.10,

(2011).

[16] U.S. EIA “Most coal plants in the United States were built before 1990.” April 2017.

\footnotetext{
${ }^{1}$ Lockwood, T., “Advanced sensor and smart controls for coal-fired power plant," IEA Clean Coal Center, No. 21, (2015). [11]

2 "Coal-Fired Electricity Generation in the United States and Future Outlook," MJB\&A Issue Brief, 1-14 (2017). [2]

${ }^{3}$ EEI Finance Department, Company Reports, S\&P Global Market Intelligence, (August 2016). [5]

${ }^{4}$ Grant, C., McCue, J., and Young, R. "The Power is On: How loT Technology is Driving Energy Innovation," Deloitte Center for Energy Solutions, Deloitte University Press, 1-24, (2016). [7]

${ }^{5}$ Miller, D. and Henly, C. "Blockchain is Reimagining the Rules of the Game in the Energy Sector," Rocky Mountain Institute, (2017), https://www.rmi.org/news/blockchain-reimagining-rules-game-energy-sector/ , accessed March 20, 2018. [13]
} 
${ }^{6}$ Starks, T., "U.S. says Russian hackers targeted American energy grid," Politico, (2018),

https://www.politico.com/story/2018/03/15/dhs-fbi-russia-hackers-targeted-energy-grid-813745, accessed March 20, 2018.

[14]

7 "Coal-Fired Electricity Generation in the United States and Future Outlook," MJB\&A Issue Brief, 1-14 (2017). [2]

8 "Coal-Fired Electricity Generation in the United States and Future Outlook," MJB\&A Issue Brief, 1-14 (2017). [2]

9 "Future of Energy: Digital for Coal-Fired Plants," GE Power Digital Solutions, (2017). [6]

10 U.S. EIA “Most coal plants in the United States were built before 1990." April 2017. [16]

${ }^{11}$ Grol, E., Tarka, T., Myles, P., Bartone, L, Simpson, J., and Rossi, G. "Impact of Load Following on the Economics of Existing Coal-Fired Power Plant Operations," DOE/NETL - 2015/1718, (2015). [8]

${ }^{12}$ Stern, D., "The Role of Energy in Economic Growth," Crawford School of Climate Economics and Policy, Paper No 3.10, (2011). [15]

13 "Future of Energy: Digital for Coal-Fired Plants," GE Power Digital Solutions, (2017). [6]

14 "DOE Laboratories Sign Memorandum of Understanding for Innovative Coal Research," March 6, 2018. [4]

${ }^{15}$ Grant, C., McCue, J., and Young, R. "The Power is On: How loT Technology is Driving Energy Innovation," Deloitte Center for Energy Solutions, Deloitte University Press, 1-24, (2016). [7]

${ }^{16}$ Budman, M., Khan, A., and Cotteleer, M., "Forces of change: Industry 4.0," Deloitte Insights, 1-20, (2017). [1]

${ }^{17}$ Budman, M., Khan, A., and Cotteleer, M., "Forces of change: Industry 4.0," Deloitte Insights, 1-20, (2017). [1]

${ }^{18}$ Louis, M., Seymore, T., and Joyce, J. "3D Opportunity in the Department of Defense: Additive Manufacturing Fires Up," Deloitte University Press, (2014). [12]

${ }^{19}$ Hiskey, T., "Preparing for Manufacturing's Future with Industry 4.0", Industry Week, http://www.industryweek.com/print/259440 accessed March 20, 2018. [9]

${ }^{20}$ Lockwood, T., "Advanced sensor and smart controls for coal-fired power plant," IEA Clean Coal Center, No. 21, (2015). [11]

21 "Distributed Energy Resources: Connection Modeling and Reliability Considerations," North American Electric Reliability Corporation, Distributed Resources Task Force Report, (2017). [3]

22 "Investigation of Smart Parts with Embedded Sensors for Energy System Applications," National Energy Technology Laboratory, Project Description, https://www.netl.doe.gov/research/coal/crosscutting/project-information/proj?k=FE0012321, accessed March 20, 2018. [10] 